\title{
¿De quién es la topografía? el plan cartográfico de la dirección de minas, geología e hidrología
}

\author{
Who does topography belong to? the mines, geology and hydrology directorate's \\ cartographic plan
}

\author{
Malena Mazzitelli Mastricchio \\ mastricchiomalena@gmail.com \\ Instituto de Investigación en Historia, Teoría y Praxis \\ de la Arquitectura y la Ciudad (HiTePAC), Facultad \\ de Arquitectura y Urbanismo de la Universidad \\ Nacional de La Plata., Argentina
}

Recepción: 24 Junio 2020

Aprobación: 14 Julio 2020

Publicación: 02 Noviembre 2020

Cita sugerida: Mazzitelli Mastricchio, M. (2020). ¿De quién es la topografía? el plan cartográfico de la dirección de minas, geología e hidrología. Geograficando, 16(2), e085. https:// doi.org/10.24215/2346898Xe085
Resumen: Durante el siglo XX existieron en Argentina dos planes cartográficos, uno correspondiente al Instituto Geográfico Militar (IGM) y el otro al de la Dirección de Minas Geología e Hidrología (DMGeH). Aunque se buscó evitar superposiciones y realizar un trabajo conjunto de provecho para ambas reparticiones, lo cierto es que la política cartográfica encarnada en el IGM terminó por centralizar y homogenizar la representación topográfica, en desmedro de algunos criterios específicos de la DGMeH. Este trabajo pretende, por un lado, echar luz sobre el plan cartográfico de la DMGeH, y, por el otro, analizar cuáles fueron las implicancias que tuvo la centralización de la cartografía para la producción de hojas topográficas de la Dirección. Presentamos primero la historia de la Dirección para visualizar cómo se fue centralizando en esa oficina pública el relevamiento topográfico; en segundo lugar, nos focalizamos en el plan de la Dirección, y, por último, en las consecuencias que tuvo la ley de la Carta en la representación topográfica. Metodológicamente se trabajó con fuentes cartográficas y escritos de las instituciones analizadas

Palabras clave: Relevamiento, Topografía, Minería.

Abstract: During the 20th century, there were two cartographic plans in Argentina: one by the Instituto Geográfico Militar (IGM, Military Geographical Institute), and the other by the Dirección de Minas, Geología e Hidrología (DMGeH, Mines, Geology and Hydrology Directorate). Although there was an attempt to avoid overlapping and carry out joint work for the benefit of both areas, the IGM's cartographic policy eventually centralized and homogenized topographic representation, to the detriment of some DGMeH-specific criteria. This article aims, on the one hand, to shed light on DMGeH's cartographic plan, and on the other, to analyze what cartography centralization implied for the production of DGMeH's topographic sheets. First, the DGMeH history is presented, to show how topographic surveying was centralized in that public division; second, the DGMeH plan is studied; finally, the Chart Law's consequences on topographical representation are discussed. Methodologically, cartographic sources and writings from the analyzed institutions were employed.

Keywords: Surveying, Topography, Mining. 


\section{INTRODUCCIÓN}

Al pensar en las prácticas de relevamiento topográfico en Argentina hacia fines del siglo XIX, dos aspectos son claros: primero, la ausencia de una institución a escala nacional, suplida en cambio por los Departamentos Topográficos en la mayoría de las provincias; y, segundo, la diferencia de la cartografía topográfica realizada por las oficinas militares respecto de la versión más sistematizada que conocemos hoy en día.

A medida que avanzaba el siglo XX, los saberes de Estado se fueron consolidando y la topografía no fue la excepción. En 1904 se creó el Instituto Geográfico Militar (IGM), que desplegó diferentes estrategias hasta su institucionalización en 1941, como la repartición oficial encargada de la cartografía nacional (Lois, 2004). Empero, el relevamiento topográfico sistemático que realizó el IGM no fue el único. Efectivamente, existió otro proyecto cartográfico de largo aliento, que, si bien tenía características diferentes, también se propuso como objetivo el relevamiento sistemático del territorio nacional. Este plan fue puesto en marcha por la Dirección Nacional de Minería y Geología e Hidrología (DMGeH) en 1911.

Este trabajo intenta echar luz sobre el plan cartográfico de la DMGeH. El objetivo es visualizar otra institución, además del IGM (actual IGN), que también se dedicó a cartografiar topográficamente el territorio, y analizar cuáles fueron las políticas institucionales que llevaron a una única manera de representación. Para ello, el trabajo se divide en cuatro partes: 1) los antecedentes institucionales de la Dirección de Minas Geología e Hidrología; 2) el contexto político y científico en que se presentó el proyecto; 3) el plan de la Dirección y sus alcances y 4 ) el impacto que tuvo la Ley de la Carta en la producción topográfica del plan.

\section{1) Antecedentes de Dirección de Minas Geología e Hidrología}

Los antecedentes institucionales de la minería en Argentina pueden rastrearse hasta 1857, cuando el presidente de la Confederación Argentina, Justo José de Urquiza (1801-1860), creó la Inspección General de Minas. Esta inspección quedó a cargo -por el decreto $\mathrm{N}^{\circ} 4176-$ del ingeniero D. Augusto Bravard (1803-1861). Con este nombramiento, Bravard realizó el Mapa Geológico y Geográfico de Entre Ríos, publicado en 1858. Años después, en 1860, mediante otro decreto se establecen las funciones de la Inspección. Entre las atribuciones que la oficina tenía figuraban la averiguación del estado y concesión de las minas, el estudio de los territorios que implicaba tanto la topografía superficial como la subterránea, la función de vigilancia y policía de las minas y las canteras. Además, debía inspeccionar a los ingenieros metalúrgicos; realizar -entre otras cosas- cartas geológicas y armar colecciones de minerales y de rocas geológicas. Inmediatamente después de ampliar las funciones de la oficina, y de poner a Bravard al frente de la Inspección, Urquiza firmó otro decreto por el que ordenó levantar el "Plano Catastral del territorio confederado" (Decreto $\mathrm{N}^{\circ} 5071 \mathrm{La}$ oficina comenzaba a tener funciones y encargados; para el trabajo catastral se le otorgaba, además, dos peones con un salario de veinticinco pesos, un ayudante con un salario de cincuenta pesos y cincuenta pesos más para gastos de papel. Ese mismo año, el Senado y la Cámara de Diputados sancionaron la creación de una plaza para un secretario de la inspección con un sueldo mensual de ochenta pesos; también destinaron fondos para el alquiler de un edificio y gastos de oficina (setecientos cincuenta y seis pesos); para la compra de instrumentos y útiles científicos se destinaros mil setecientos pesos.

A pesar de estas funciones, con la muerte de Bravard en el terremoto de Mendoza de 1861, el Ministerio del Interior - del que dependía la Inspección de Minas- comunicó el cierre de la oficina y se canceló el dinero para el alquiler. Todas las pertenencias de la oficina -como los muebles y los útiles-fueron archivadas en una 
pieza del museo. De esta manera, quedaron vacantes todos los puestos de empleados. El proyecto del mapa catastral no se abandonó, por su importancia en infraestructura y la demarcación técnica. ${ }^{2}$

Años más tarde, en noviembre de 1868, el presidente Domingo F. Sarmiento (1811-1888) nombró por decreto $\mathrm{N}^{\circ} 7204$ al sargento mayor Ignacio Richard (o Rickard) como nuevo inspector de minas de la república. Por este cargo Richard recibiría un salario mensual de ciento veinticinco pesos fuertes. Mientras estuviera de comisión se le asignaba, además, un viático de cuarenta pesos fuertes mensuales para cubrir los gastos extras que tenían las campañas. El objetivo por el cual fue contratado este sargento mayor consistía en visitar las minas de diferentes provincias. ${ }^{3}$ En su recorrido debía informar diferentes aspectos que tenían que ver con la riqueza y potencialidad de las minas (metales explotados y no explotados; minerales útiles para la industria o auxiliares para la minería, etc.). También debía informar sobre el capital humano y económico con que se contaba en las minas (cantidad de trabajadores, maquinaria utilizada para el sistema extracción, tipos de inconvenientes, etc.).

Como fruto de esta contratación y de su trabajo, Ignacio Rickard presentó un informe denominado Informe sobre los Distritos Minerales. Minas y establecimientos de la República Argentina 1868-1869, que fue publicado de manera oficial por el Ministerio del Interior en 1869. Las palabras del mismo Ignacio Rickard nos dan una idea del escaso conocimiento que se tenía del estado de la minería en esta época:

He tenido que luchar con muchos inconvenientes y trabajar incesantemente para formar la estadística que acompañó mi informe, pues son raros los casos en que los mineros (...) lleven libros o cuentas; son por lo general poco atentos a los gastos y productos y muy pocos podían darme cuenta de ellos. Los Gobiernos de las provincias (...) saben menos de la minería en su misma jurisdicción, que el más casual observador. De esta apatía nace la falta de interés y completa carencia de datos fidedignos sobre su importancia; y cuanto por casualidad se ocupa de ella es para decretar impuestos y derechos que solo tienden a matarla antes que nazca.

Si el Gobierno Nacional no tiende la mano para proteger la industria en el país, y dictar leyes adecuadas y favorables al caso, temo que los actuales laboriosos capitalistas que se ocupan de ella, se aburran con las continuas luchas y abandonen sus faenas (Rickard, 1869, p. 4).

La cita es muy elocuente en cuanto al estado de la industria minera y la falta de una oficina técnica que organice y centralice la labor, pero sobre todo visibiliza la necesidad de que el Estado pudiera sacar ventajas económicas de los recursos naturales. ${ }^{4}$

A pesar de dejar clara la necesidad de establecer políticas centralistas, en los años subsiguientes hubo nombramientos de responsables de minería en los colegios nacionales de diferentes provincias, ${ }^{5}$ pero para la centralidad institucional estatal hubo que esperar hasta 1885 cuando se creó la Sección de Minas dependiente del Ministerio del Interior, que quedó bajo la dirección de Luis Albertini (SEGEMAR, 2004; Reverberi, 2004; Camacho, 2002 y 2008; Riccardi, 2016). El principal objetivo de esta nueva oficina técnica consistía en realizar estudios geológicos, mineros e hidrológicos en todo el país. Para ello se dotó a la institución de un laboratorio que permitía realizar ensayos minerales de las muestras recolectadas en algunas provincias, tales como Córdoba, La Rioja, Santiago del Estero y también en la Patagonia (Reverberi, 2004).

En 1887 la Sección de Minas pasó a constituirse en el Departamento de Minas y Geología, y fue la primera vez que en el título de la institución aparece mencionado explícitamente la ciencia geológica. La nueva oficina, que dependía del Ministerio de Hacienda, estuvo a cargo del inglés Herny David Hoskold ${ }^{6}$ (1829-1904), quien fue el primero en diseñar un plan cartográfico que incluyó tanto la representación de la geología como de la topografía a escala 1:200.000 (Page, Mendía, Mazzitelli Mastricchio y Folguera, 2014) tal como, efectivamente, se llevaría a cabo con posterioridad.

La institución mantuvo su organigrama bastante estable hasta que, casi diez años después, pasó a llamarse División de Minas y Geología, y a depender del Ministerio de Agricultura (1898). Paralelamente, en el Ministerio de Agricultura funcionaba, desde el 8 de febrero de 1902, la Comisión de Estudios de Napas y Yacimientos Carboníferos. Esta oficina estaba a cargo del ingeniero argentino Enrique Hermitte ${ }^{7}$ (1871-1955), y se proponía relevar el territorio nacional para detectar agua, carbón, minerales y petróleo. 
También se dedicaba a recopilar los antecedentes, estudios y publicaciones sobre temas relacionados con el agua y los hidrocarburos que involucraban al país (SEGEMAR, 2004; Riccardi, 2016).

Dos años más tarde, en 1904, se unieron ambas oficinas. El Departamento de Minas y Geología, que dirigía Hoskold, y la Comisión de Estudios de Napas y Yacimientos Carboníferos, que dirigía Hermitte, se fusionaron en la División de Minas, Geología e Hidrología (DMGeH), la cual, tras la muerte de Hoskold ese mismo año quedó a cargo del ingeniero Hermitte. La División cumplía funciones administrativas y tenía jurisdicción en todo el territorio argentino, incluyendo los Territorios Nacionales.

Con la creación de la División de Minas, Geología e Hidrología se organizaron tres secciones especializadas: la Sección de Minas, a cargo del Ingeniero Juan Sol; la Sección de Geología, a cargo de Juan Keidel, y la Sección de Hidrología, a cargo de Julio Krausse (Reverberi, 2004).

Simultáneamente a su trabajo a cargo de la Dirección, Hermitte se desempeñaba como profesor en la Universidad de Buenos Aires. Esto le permitió reclutar estudiantes con orientación en Geología para llevarlos a la División de Minería, Geología e Hidrología para que completaran sus estudios y formación trabajando con los geólogos extranjeros ${ }^{8}$ (García, 2016). Es evidente que se estaba armando un cuerpo de expertos estatales que se encargarían del relevamiento geológico y minero del país, para lo que se necesitaba una base topográfica acorde.

En 1912 la División pasó a ser Dirección Nacional de Minería, Geología e Hidrología. A pesar de todos los cambios que siguieron transformando el nombre de la Dirección desde 1912 hasta la década de 1980, la institución mantuvo el mismo proyecto de relevamiento del territorio: el Mapa Geológico-Económico de la República Argentina. Por este motivo, y para no confundir al lector, en este trabajo hacemos uso del nombre Dirección Nacional de Minas, Geología e Hidrología, independientemente de las denominaciones que tuvo en los diversos momentos históricos.

A pesar de que la DMGeH interactuaba con otras instituciones científicas que también producían cartografía, como el Instituto Geográfico Militar ${ }^{9}$ (1904-2009), tenía sus programas, métodos y las normas de trabajo, que eran particulares y que se convirtieron en lo que podemos llamar "culturas visuales particulares (...) en las que se observa que una serie de prácticas visuales, hechas hábitos en los espacios de formación y de trabajo, se convierten en maneras de mirar, y sobre todo, de resolver problemas" (Favelukes, 2011, p. 2).

Efectivamente, la dirección contaba con instructivos y el trabajo empírico suficiente para construir un oficio que derivó en una cultura visual particular, al menos hasta la década de 1940. En este contexto, la Sección Topografía creada en 1912 organizó sus propios proyectos y campañas de trabajo de campo.

FIGURA 1

Línea de tiempo

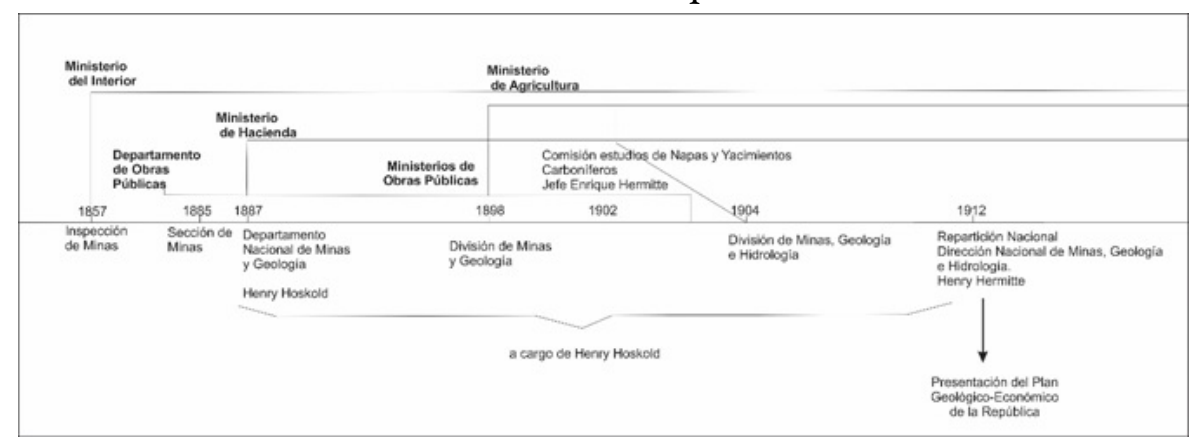

Fuente: Elaboración propia con base en información de fuentes documentales. 


\section{UN PLAN DE RELEVAMIENTO PARA EL TERRITORIO ARGENTINO}

En 1911 Hermitte diseñó el programa de relevamiento sistemático del territorio nacional, que se llamó Plan Geológico Económico de la República Argentina. En el plan se proponía realizar al mismo tiempo el relevamiento topográfico y geológico del territorio. Tenía varios objetivos: el primero era realizar estudios regionales, que implicaban utilizar las escalas 1:1.000.000 y/o 1:500.000; el segundo consistía en realizar estudios temáticos, como los que ya se venían realizando en la institución, y el tercero era realizar un levantamiento sistemático a escala 1:100.000 y su posterior publicación a escala 1:200.000 (Page et al., 2014).

Para llevar a cabo este proyecto, Hermitte consideraba indispensable un estudio integral que incluyera el levantamiento de la hidrología, la minería, la geología, pero también de la topografía, porque consideraba que sin el estudio de las formas del terreno la representación de los otros saberes era imposible. Así fue que, en las memorias de 1913, publicadas dos años después, el jefe de la Dirección explicaba la importancia de la topografía, pues "el conocimiento preciso de la superficie debe preceder (...) o por lo menos acompañar a las investigaciones geológicas, mineras y de hidrología subterránea” (Hermitte, 1914, p. 14). Por esta razón, la Dirección había creado en 1912 la sección Topografía, que sería la responsable de realizar los mapas topográficos que servirían de base a la cartografía geológica y los datos hidrológicos. Esto suponía una disputa por el campo del saber topográfico con el Instituto Geográfico Militar, que tenía entre sus objetivos realizar el mapa civil de la república, lo cual propuso formalmente en 1912, cuando presentó su proyecto cartográfico denominado Plan de la Carta (Mazzitelli Mastricchio, 2007).

Hermitte objetó que el Estado hubiera confiado exclusivamente en instituciones militares los trabajos topográficos, porque las instituciones militares "tienen un punto de vista espacial y no están en condiciones de consultar todas las necesidades materiales del Estado” (Hermitte, 1914, p. 12). Para él, la única lógica que tenía la decisión de haber dejado en manos del Instituto Geográfico Militar el levantamiento topográfico del país se debía más a una tradición que a una decisión científica o de capacidades técnicas. Ante la falta de un mapa concreto topográfico que satisficiera las necesidades de la geología e hidrología, Hermitte reclamaba que su propio cuerpo de topógrafos y cartógrafos realizara los trabajos que la Dirección necesitaba. Se comprometía, además, a que no surgiera superposición de trabajos con la institución militar.

El problema que planteaba Hermitte consistía en que con el personal que contaba le iba a llevar 74 años el relevamiento completo del país, ya que la sección topográfica tenía poco personal capacitado para realizar las tareas que se proponía (Tabla 1). En cambio, proponía que la conformación de la oficina topográfica de la DMGeH debía contar con un geodesta especialista en astronomía, seis geodestas (tres de primera y tres de segunda) y siete topógrafos (tres de primera, dos de segunda y dos de tercera); cuatro cartógrafos (dos de primera y dos de segunda) y tres dibujantes. Justificaba su pedido a través de la comparación entre el personal de la Dirección de Minas y el personal de otras oficinas como la de IGM y sus pares en Alemania e Italia (Tabla 2). 
TABLA 1

Cantidad de personal de la Oficina de Topografía de la DMGeH, 1912

\begin{tabular}{|l|l|}
\hline \multicolumn{2}{|l|}{ Personal de topográfico de la DMGeH } \\
\hline Cargos & $\begin{array}{l}\text { Cantidad de } \\
\text { personal }\end{array}$ \\
\hline Jefe & 1 \\
\hline $\begin{array}{l}\text { Topógrafo de } \\
\text { primera }\end{array}$ & 1 \\
\hline $\begin{array}{l}\text { Cartógrafos de } \\
\text { primera }\end{array}$ & 2 \\
\hline $\begin{array}{l}\text { Topógrafos de } \\
\text { segunda }\end{array}$ & 1 \\
\hline $\begin{array}{l}\text { Cartógrafo de } \\
\text { segunda }\end{array}$ & 1 \\
\hline $\begin{array}{l}\text { Topógrafos de } \\
\text { tercera }\end{array}$ & 2 \\
\hline Total & 8 \\
\hline Presupuesto & $5.000 \$ \mathrm{~m} / \mathrm{n}$ \\
\hline
\end{tabular}

Fuente: Elaborado con base en la Memoria de la Dirección de Minas Geología e Hidrología de 1914.

TABLA 2

Comparación de la cantidad de personal de las oficinas topográficas

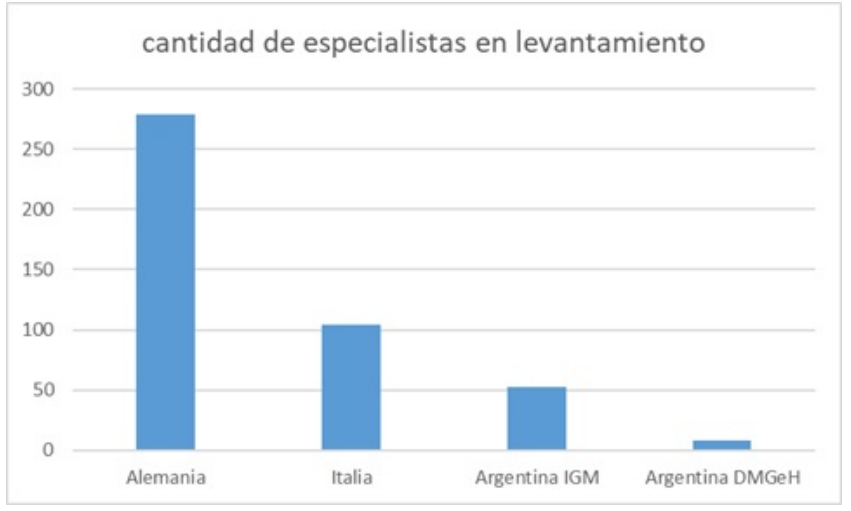

Fuente: Elaborado con base en la Memoria de la Dirección de Minas, Geología e Hidrología de 1914

A pesar de conocer esta escasez de capital humano y financiero que dificultaba afrontar los gastos que implicaba un relevamiento de este tipo, el Plan Geológico Económico de la República Argentina fue presentado en 1911 por el jefe de la sección Geología, Keidel, en el XII Congreso Geológico Internacional, que se celebró en Toronto. A pesar de su escasa viabilidad, la necesidad de presentar un plan de estas características a la comunidad científica internacional, radicaba, en primer lugar, en que la Argentina se postuló en ese momento como sede del congreso a realizarse en 1920. La aceptación fue unánime. Pero no bastaba con presentar la propuesta, se debía demostrar que el país contaba con proyectos científicos acordes a los que se realizaban en países pujantes como Canadá. Este marco de la presentación del plan de Keidel explica la premura en hacer público un plan que distaba de estar en condiciones de ser ejecutado. No obstante, tanto Keidel como Hermite tenían presentes las dificultades que presentaba el plan, por eso reclamaban más cantidad de profesionales para la sección topográfica.

Por otro lado, Hermitte apoyó sus reclamos de aumentar la cantidad de técnicos comparando la extensión del territorio argentino con el canadiense. Esta comparación era una práctica habitual para evaluar planes de estas características, ya que se pensaba que a igual cantidad de $\mathrm{km}^{2}$ por recorrer se tardaría la misma cantidad de tiempo. Este tipo de comparaciones lineales entre los kilómetros cuadrados y el tiempo de levantamiento 
no son del todo reales si no se tiene en cuenta la necesidad de contar con capital técnico, humano y financiero para hacer frente a trabajos de tal envergadura. Hermitte estaba al tanto de esta necesidad, por eso reclama al ministro que si la Argentina quería contar con un mapa integral de su territorio en 15 años, tal como había hecho Canadá, debía disponerse de 15 comisiones con sus respectivos topógrafos en lugar de las dos que existían hasta ese momento.

A pesar de todas las idas y vueltas y de lo ambicioso que resultaba el proyecto, el plan fue puesto en marcha y estuvo vigente hasta la década 1980, aunque no fue concluido. En la actualidad, solo el 19,3\% del total fue relevado a escala $1: 100.000$ y publicado a escala $1: 200.000^{10}$.

\section{El PLAN DE RELEVAMIENTO: TÉCNICA, SOBERANíA Y REPARTICIONES}

El proyecto consistía en un plan sistemático que dividía el país en 618 láminas completas y 198 incompletas (Memoria DHMeH, 1912). La grilla que dividía el territorio contaba con una nomenclatura particular: el país se dividía de norte a sur y cada paralelo llevaba un número comenzando en el norte con el número 1, hasta la cartografía más austral con el número 68. Por otro lado, se volvía a dividir de oeste a este colocándole una letra a a las hojas ubicadas al oeste, hasta llegar a la letra s en las hojas más cercanas al este (Figura 2). La grilla serviría tanto para la representación topográfica como geológica, y cada hoja contenía en promedio 4.000 kilómetros cuadrados. La grilla se diseñó con la intención de que el trabajo de relevamiento sea lo más regular posible, en tanto el tamaño y dimensiones elegidas apuntaban a que "cada una de ellas [fuera] una lámina de tamaño cómodo para la impresión y empleo de la misma” (Hermitte, 1914, p. 13).

FIGURA 2

Grilla presentada en la Memoria de 1912 de la Dirección de Minas, Geología e Hidrología

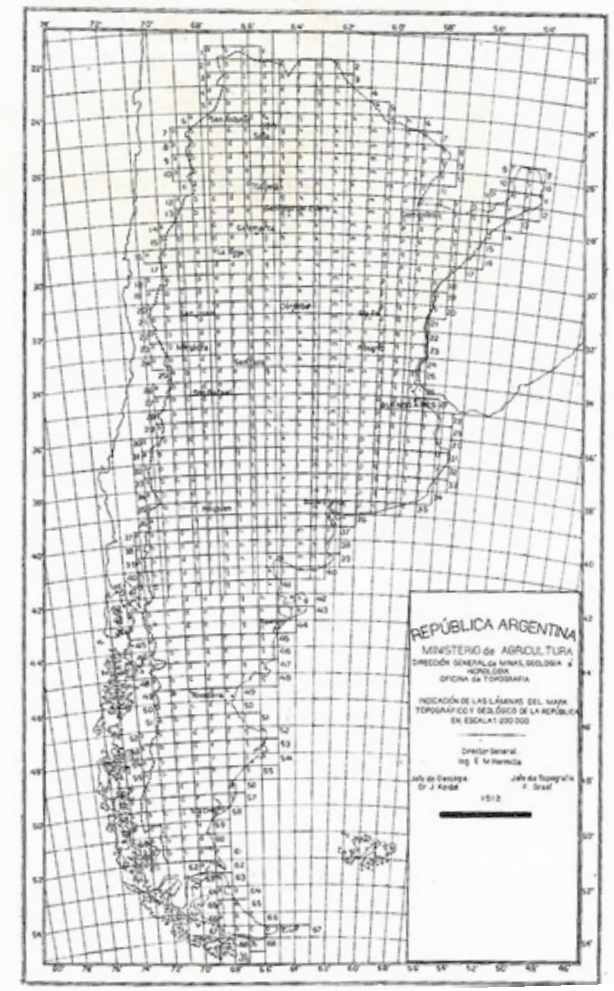

Fuente: Dirección de Minas, Geología e Hidrología

La elección de la escala de relevamiento y de publicación tuvo que ver, como el mismo Hermitte lo reconoce, con una serie de circunstancias: según el director de la institución, la escala a 1:200.000 era más 
rápida y menos costosa que los levantamientos realizados con el instrumental de la plancheta que proponía el Instituto Geográfico Militar. Además, era la escala que había sido reconocida universalmente como la más acertada para países nuevos y con la extensión territorial de la Argentina (Hermite, 1914). Para sitios de interés especial se podría utilizar una escala que implicara mayor detalle (Hermite, 1914). Asimismo, Hermitte reconoce que faltaba una triangulación geodésica, que permitiera realizar un levantamiento a escalas mayores (1:100.000), y que incluyera un mayor detalle, como proponía el Instituto Geográfico Militar. Efectivamente, el IGM proponía en su Plan de la Carta realizar una red con precisión geodésica de puntos altimétricos y planimétricos para toda la república. Esta propuesta tuvo oposición y fue discutida en el seno mismo del Instituto Geográfico Militar. La discusión se centraba en que una parte del plantel de los técnicos que conformaba el Instituto consideraba que una red geodésica era imposible de realizar en las condiciones técnicas y financieras con que contaba el IGM. Sin embargo, la dirección del Instituto siguió adelante con el plan, aunque luego tuvo que readaptarlo a las posibilidades nacionales (Mazzitelli Mastricchio, 2007; 2011). Como ya señalamos en un trabajo anterior, el plan del IGM de 1912 debe leerse en el marco técnico y científico internacional, ya que, en caso de no existir un proyecto cartográfico nacional para Argentina, la cartografía a escala 1:1.000.000 -llevada adelante en esos años con esfuerzo internacionalhabría sido realizada por una potencia cartográfica internacional, tal como había sido el caso de Japón, que fue relevado por Alemania. En este sentido, el plan que propuso el IGM estaba orientado más a fortalecer la soberanía cartográfica que a proponer y gestionar un plan factible de ser realizado (Rieznik y Lois, 2010; Mazzitelli Mastricchio, 2012).

Hermitte estaba al tanto de las discusiones que se establecían en el seno del IGM, ya que él mismo formaba parte de la Comisión de la Carta. Es de suponer que conociera bien sus faltas y la dificultad de trazar una red de puntos con precisión geodésica. Por esta razón Hermitte proponía que la Dirección de Minería Geología e Hidrología debía realizar una "triangulación general por la determinación directa de las coordenadas geográficas de los vértices, cuya exactitud es suficiente para una escala 1:200.000” (Hermitte, 1914, p. 13).

Sin embargo, como lo demuestra Crone (2000) para el caso inglés, la elección de las escalas no es una cuestión únicamente técnica, sino que implica discusiones políticas. Por esta razón, a pesar de las dificultades técnicas que influían en la elección de la escala, la selección de la una precisión 1:200.000 puede leerse también como una estrategia institucional para no superponer trabajos con el Instituto, que, por esos años, pugnaba por quedarse como único referente de la cartografía topográfica de la Argentina (Lois, 2004). Por otro lado, para volver visible la geología se hacía necesario contar con una base topográfica, aunque no tuviera precisión geodésica, porque es la forma del terreno la que le indica al geólogo los procesos geológicos ocurridos. De hecho, ante la necesidad de contar con un mapa topográfico que permitiera construir el mapa geológico del país, la dirección publicó en 1914 el primer Mapa Hipsométrico de la República Argentina y regiones limítrofes, que tenía un tamaño de $80 \mathrm{~cm}$ por $47 \mathrm{~cm}(\mathrm{DGMeH}, 1914$, p. 89). Es evidente que la DMGeH estaba dispuesta a ceder en la precisión de sus mapas topográficos para poder cumplir con su plan, que, además de ser geológico, era, como su nombre lo indica, económico.

Durante la primera década del siglo XX se relevaron diecinueve hojas topográficas, la mayoría, en provincias con tradición minera, como Salta, Catamarca, San Juan, Córdoba, Río Negro, Chubut, y Buenos Aires. Sin embargo, solo fueron publicadas dos, una correspondiente a la hoja de Bahía Blanca en la provincia de Buenos Aires y la otra a la provincia de Salta. El plan establecía que cada sector cartografiado comprendiera a su vez tres mapas diferentes: uno geológico, otro topográfico y el tercero que se llamaría de elementos complementarios. La hoja geológica era la única que iba acompañada con un libro en el que el geólogo interpretaba el mapa. La única hoja que se relevó con la serie completa, es decir, las tres cartas, fue la hoja Bahía Blanca (35-m) (Figura 3). El levantamiento del territorio fue aumentando y en la década de 1940 se llegó al pico de más alta de producción, de hecho, el $22 \%$ de todas las hojas publicadas se hicieron en esta década (Tabla 3). La disminución comenzó a sentirse en la década de 1960 y se hizo más evidente en las décadas 
siguientes, hasta que fue directamente remplazado por la topografía del IGM. En la Figura 4 se muestra la cantidad de hojas levantadas por décadas, y en la Figura 5 se aprecia la cantidad de hojas publicadas por década.

TABLA 3

Porcentajes de hojas topográficas editadas por la DMGeH

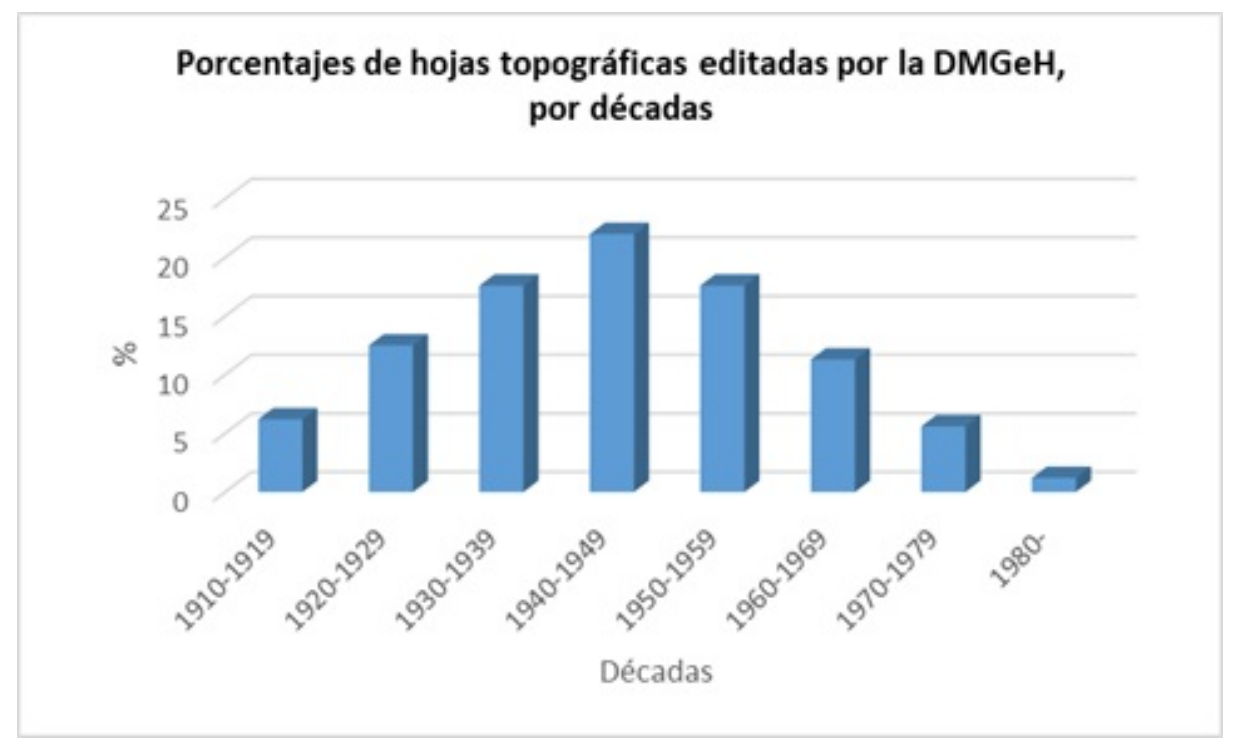

Fuente: Elaboración propia con base en datos del SEGEMAR

\section{FIGURA 3}

Hoja geológica, topográfica y de datos complementarios de Bahía Blanca. SEGEMAR

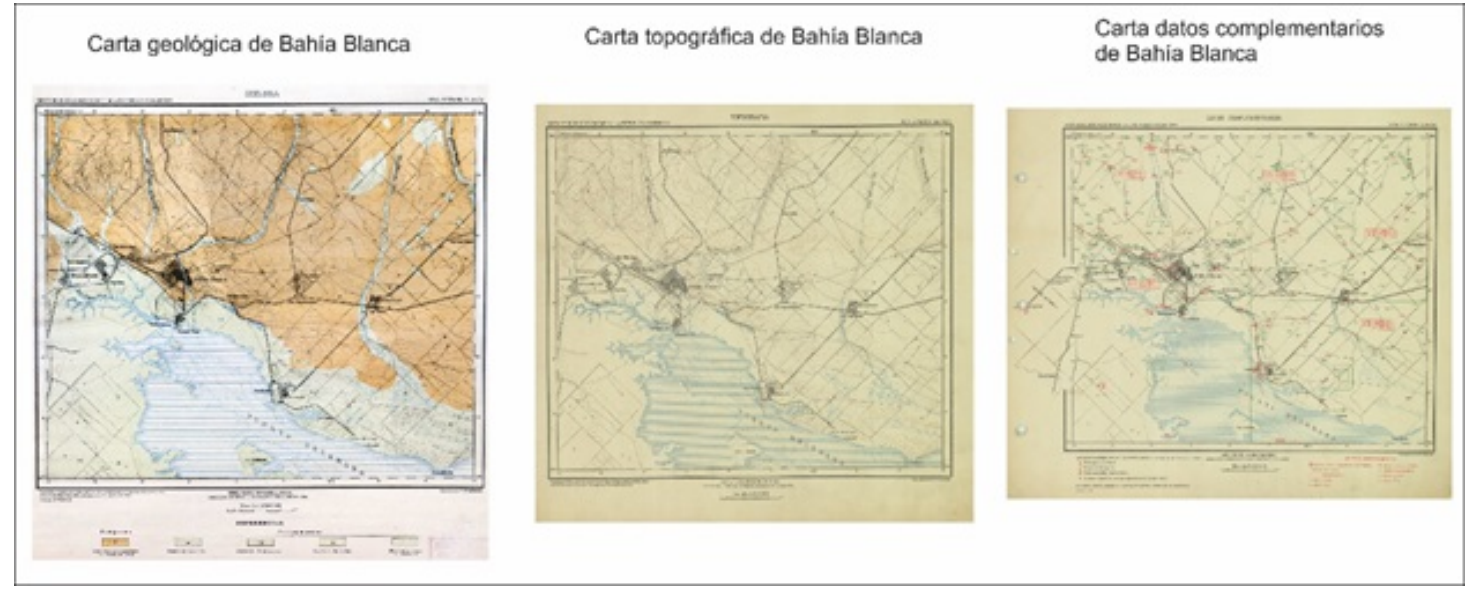

Fuente: SEGEMAR. 
FIGURA 4

Esquema de hojas topográficas de la DMGeH levantadas por décadas
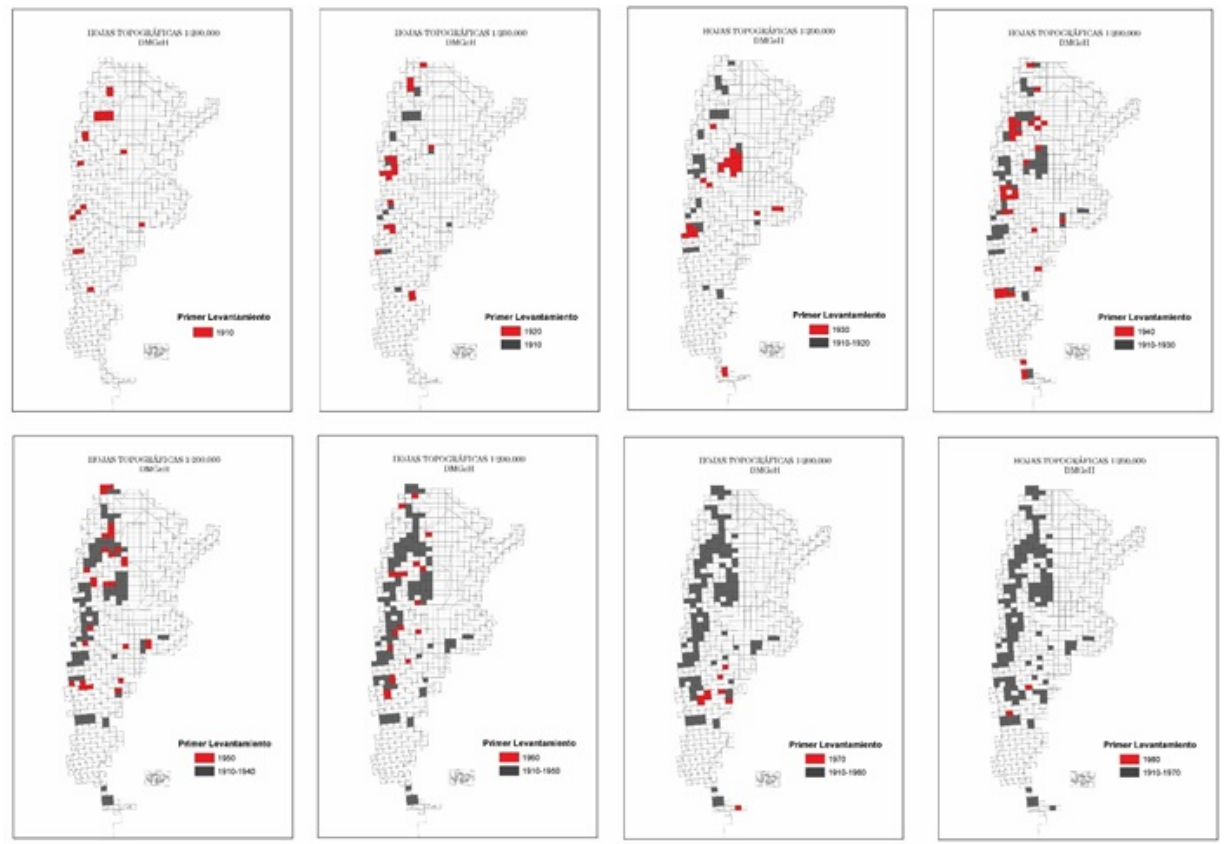

Fuente: elaboración propia con base en las hojas topográficas del SEGEMAR.

\section{FIGURA 5}

Esquema de hojas topográficas de la DMGeH publicadas por décadas
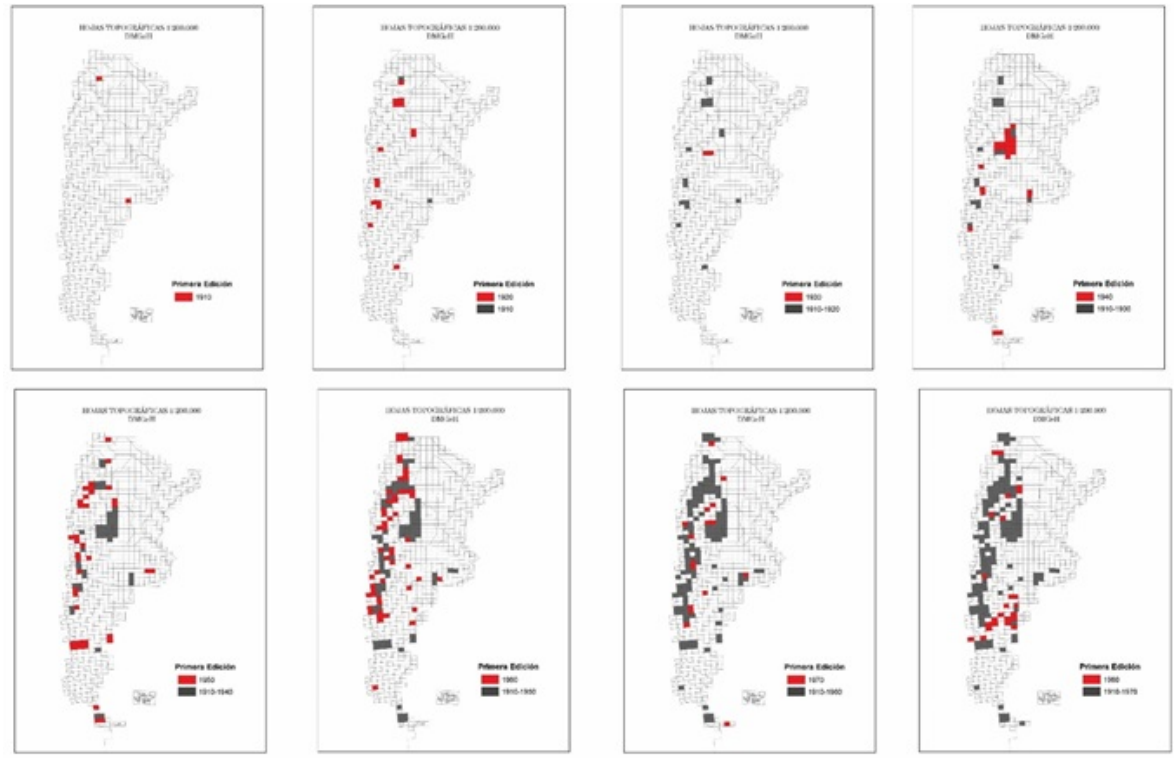

Fuente: elaboración propia con base en las hojas topográficas del SEGEMAR.

\section{LA PÉRDIDA DE LA ESPECIALIZACIÓN TÉCNICA Y VISUAL}

Es evidente que la Dirección de Minas y Geología e Hidrología estaba capacitada para realizar su propia topografía, de hecho, el proyecto estuvo en marcha por casi setenta años. De acuerdo al plan, cada hoja topográfica debía mantener la misma uniformidad visual, es decir, se utilizaría en su confección el mismo sistema de representación, signos convencionales, tintas, etc. (Memoria de la DMGeH, 1912). La Dirección 
publicaba sus propias normas y pautas de trabajo tanto para la representación geológica como para la topográfica. Podemos decir que la topografía de la $\mathrm{DMGeH}$ seguía casi en un todo sus propias reglas: equidistancia, colores, convenciones, topónimos y grilla.

A partir de la década de 1940 la sanción de la ley de la carta introdujo un cambio importante en la historia de la cartografía nacional. Esta ley le otorgó al Instituto Geográfico Militar la potestad de la representación del territorio nacional (Lois, 2004; Mazzitelli Mastricchio, 2017). Sin embargo, en esos años se produjo la mayor publicación de hojas topográficas de la DGMeH. Es más, a pesar de la existencia de la ley, la Dirección siguió realizando su propia topografía durante 40 años más. Cabe preguntar entonces, ¿cuáles fueron las consecuencias de esta ley en la producción de cartografía topográfica de la DMGeH? Lejos de dar una respuesta única, intentaremos desentrañar algunas cuestiones que, creemos, llevaron a que prevaleciera una forma de visualizar y de pensar el territorio. Creemos que la homogeneización y la potestad de una única institución no se explican estrictamente a partir de qué institución realiza el relevamiento, o por las cuestiones técnicas (escala, grilla, equidistancias), sino por el hecho de la mayor centralización de la topografía. Esto produjo normas que fueron limitando la manera de representar. Es decir, se normaliza la forma en que se dibuja y representa el terreno, los colores utilizados en el relieve, los procedimientos con que se simplifican las curvas de nivel, la tipología utilizada para los topónimos y otras leyendas que hacen al mapa -como el recuadro que engloba al terreno-, la disposición de elementos decorativos, etc. En la Figura 6 elegimos una carta topográfica realizada por la DMGeH a principios del siglo XX y otra de la misma región realizada después de la década de 1940. ${ }^{11}$ Ambas hojas son consecutivas en la grilla, es decir, una está al lado de la otra, por lo que la geografía no cambia demasiado en tre una y otra. Sin embargo, como vemos en nuestras imágenes, la visualidad del mapa es totalmente diferente. La primera de las hojas corresponde a la hoja topográfica Rosario de Lerma (7d), que fue relevada en 1912 y editada en 1919; la segunda hoja corresponde a la carta topográfica Nevado de Cachi (7c), que fue editada en la década de 1960 (Figura 6).

A primera vista encontramos que cambia la información que acompaña el recuadro del mapa. En la primera encontramos la información sobre la autoría del mapa: que el dibujo se realizó en 1918 por los topógrafos $\mathrm{P}$. Scheizer y J. Jenkner, y sus relevamientos fueron realizados por el jefe de topografía Graef, los topógrafos R. Pusch y T. Hofmann, quienes hicieron un levantamiento estéreo fotogramétrico entre 1912 y 1913, y Walter Anz, quien en 1915 realizó un levantamiento rápido. En la imagen de 1960 no figuran los topógrafos ni los cartógrafos que realizaron el mapa. Es una cartografía, como plantean Nadal y Urteaga (1990), sin autor. Este proceso que estudian Nadal y Urteaga para la cartografía europea del siglo XIX, en nuestro país no se da de forma lineal en todas las instituciones. Veamos qué sucede en la $\mathrm{DMGeH}$ : podemos dividir el formato de las hojas topográficas de la Dirección en dos grupos; uno es el formato de la hoja Rosario de Lerma (7d) y el otro formato es el de la hoja topográfica Nevado de Cachi (7c).

La primera serie estuvo en marcha desde el inicio del plan hasta la década de 1940, de hecho, la hoja más nueva que encontramos con este formato corresponde a 1944 (Quines, en la provincia de San Luis). Mientras estaba en funcionamiento esta serie, todas las hojas contaban con la información de los autores; cuando la serie cambió al nuevo formato, los autores desaparecieron de casi todas las hojas, pero no en todas. ${ }^{12}$ La especialización y homogenización de la representación topográfica parece indicar que la topografía no es una interpretación, sino que es siempre la misma y los autores no son lo más relevante; en otras palabras, los autores van perdiendo relevancia ante el fortalecimiento de las instituciones.

La autoría no es la única diferencia. Veamos los títulos: en la primera serie el título que aparece en el centro es "Topografía”, en el margen izquierdo aparece el nombre del plan cartográfico y en el margen derecho la nomenclatura de la hoja, que en este caso es $7 \mathrm{~d}$ y entre paréntesis el topónimo (Figura 7) (recordemos que por cada hoja topográfica debía hacerse su par geológica, la cual llevaba el mismo título solo que se remplazaba topografía por geología). Notamos que en esta serie no está incluida la provincia; creemos que esta falta tiene que ver con la especialización de la Dirección y su objetivo. Pues no era el mapa de la república, la confección de este mapa estaba bajo la órbita del IGM; el mapa de la DMGeH estaba orientado a ser de apoyo a la geología 
y esta no respeta límites administrativos, por lo tanto, no eran necesarios, pero, sobre todo, se dejaba claro que la Dirección no estaba confeccionando el mapa topográfico de la Argentina.

En cambio, en la época en que se editó la segunda hoja topográfica las condiciones de la política cartográfica del Estado argentino habían cambiado; el IGM ya encabezaba la producción de la cartografía nacional y los campos de trabajo estaban bien definidos entre ambas instituciones. En este contexto, el IGM influye (e impone) una manera de representación. Veamos cómo se ve en la representación de la topografía de la Dirección de Minas, Geología e Hidrología. La hoja, que pertenece a la segunda serie, tiene una distribución muy diferente que la primera. En primer lugar, el título que predomina es el topónimo de la hoja: Nevado de Cachi (Figura 6), inmediatamente después aparece el nombre de la provincia, de manera tal que el lector especializado puede ubicarse rápidamente en la geografía de la Argentina. En el margen izquierdo aparece la institución y su logo; en el margen derecho la inscripción "base topográfica para la Carta Geológica Económica de la República Argentina” y la nomenclatura (Figura 8). Sabemos que para la década de 1960 el plan topográfico del IGM todavía distaba mucho de estar terminado, por lo que debía ser interesante contar con la topografía de las provincias independientemente de que institución lo hiciera. El avance en la visualidad, por parte de IGM en las hojas topográficas de la Dirección puede leerse (además de la homogenización de las técnicas de dibujo y de representación) como la necesidad del Estado por contar con mapas topográficos lo más estandarizados que se pueda, independiente de la precisión, la escala y las instituciones que los realicen.

FIGURA 6

Hojas topográficas
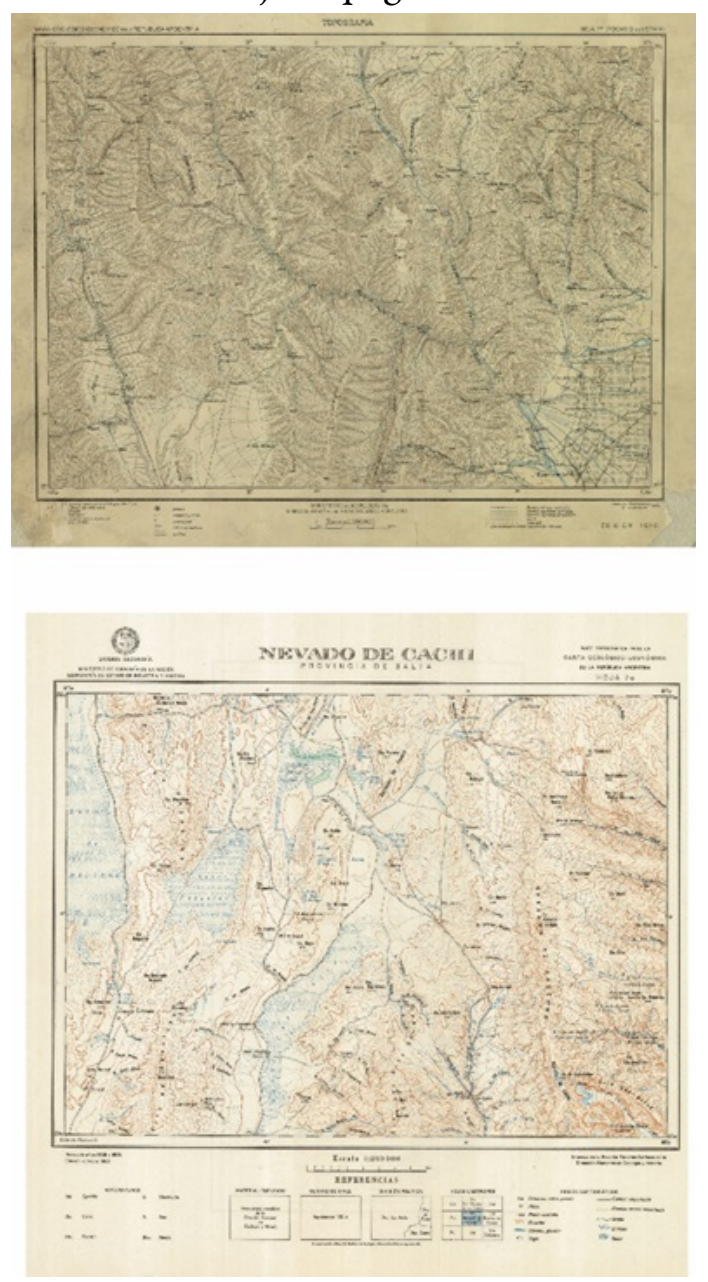

Fuente: SEGEMAR. 
FIGURA 7

Recorte de la hoja topográfica 7d

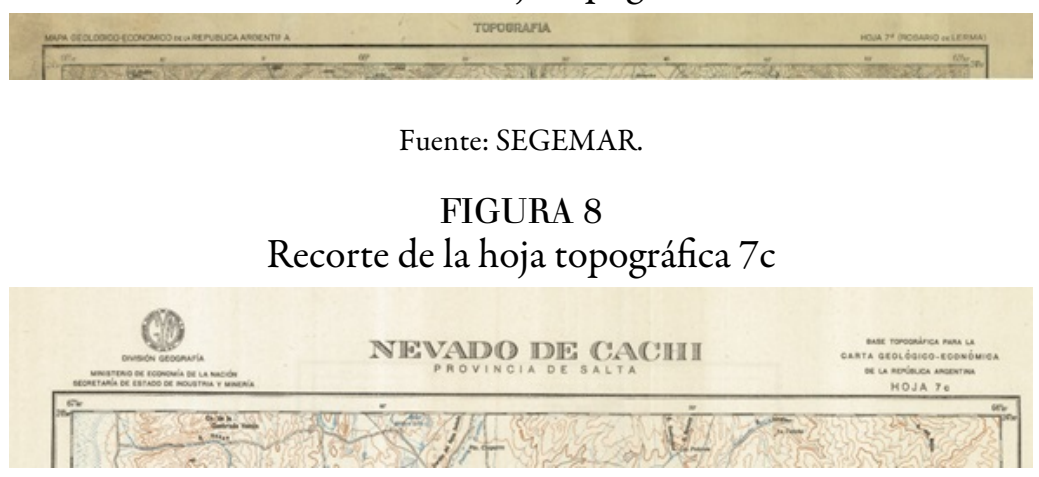

Fuente: SEGEMAR

Efectivamente, estos cambios deben enmarcarse en la política cartográfica del Estado argentino. Diez años antes de la sanción de la Ley de la Carta de 1941 el IGM publicó un manual de cartografía, más precisamente de signos cartográficos. Esta publicación produjo una normalización, entre otras cosas, en los colores de los topónimos de la hidrología y el color en las curvas de nivel. Esto llevó a que la Dirección reeditara las hojas topográficas publicadas con anterioridad, adaptándose a estas nuevas normas. Esta reedición de hojas comenzó a partir de la década de 1940 cuando las normas establecidas por el IGM se volvieron obligatorias para todas las instituciones productoras de cartografía, tal como obligaba la Ley de la Carta. Por ejemplo, la nueva distribución de títulos de las hojas topográficas responde al modelo de plancheta que el Instituto había establecido para 1909 y reafirmado, con algunas modificaciones, en 1930. Ese año el IGM agregó como obligatorio incluir los gráficos explicativos, que mostraban la situación relativa de las hojas, esto es, la subdivisión política y administrativa del territorio representando la ubicación de la hoja dentro de la grilla (Figura 9).

FIGURA 9

Gráficos ilustrativos IGM Hoja topográfica Goya 2960-23

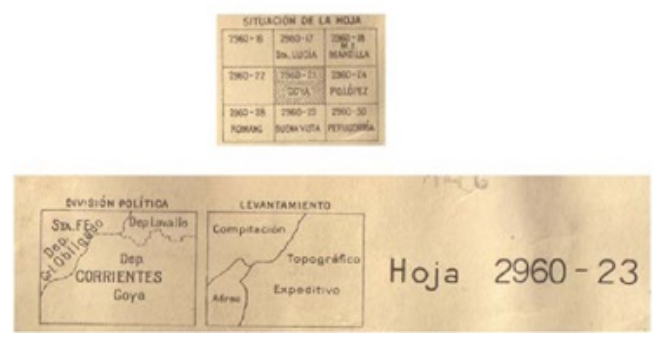

Fuente: IGM.

El cambio en la representación altimétrica se concentró en homogeneizar los signos cartográficos que representaban las curvas. Serían, en primer lugar, una línea fina para las curvas equidistantes o intermedias; una línea gruesa para las curvas principales o directrices y una línea punteada para representar las curvas auxiliares (IGM, 1979, p. 156). Este cambio implicó la eliminación de cualquier otro signo para representar el relieve, como las “achuras" entre curva y curva de nivel (Figura 10). Solo se permitiría la línea de la curva para representar el volumen del terreno (Figura 11). La eliminación de las achuras significó un cambio importante en la visualidad de las hojas topográficas de la Dirección de Minas, Geología e Hidrología. 
FIGURA 10

Hoja topográfica de la DMGeH, con detalle de representación del relieve y leyenda antes de 1940

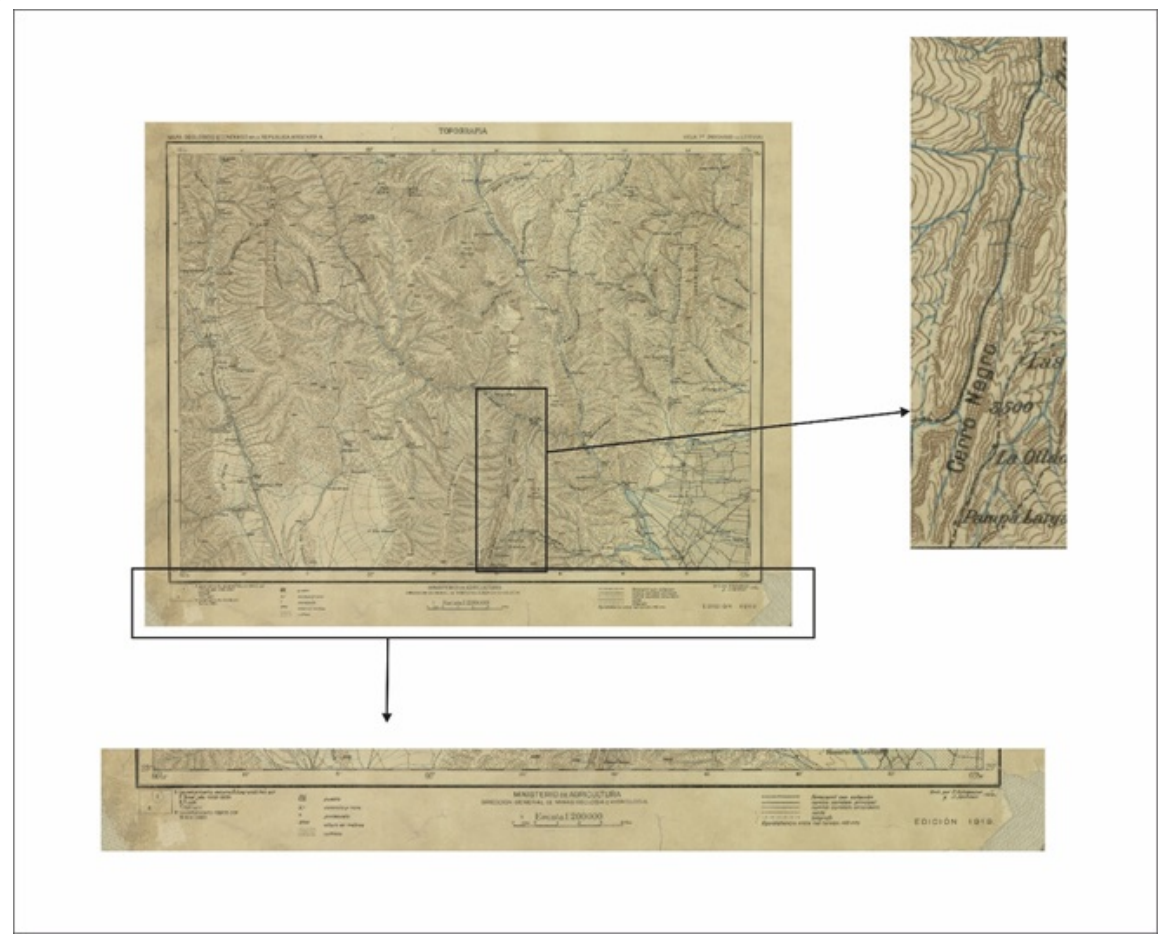

Fuente: Esquema de elaboración propia con datos del SEGEMAR.

FIGURA 11

Hoja topográfica de la DMGeH con detalle de representación del relieve y leyenda. Editada en octubre de 1960

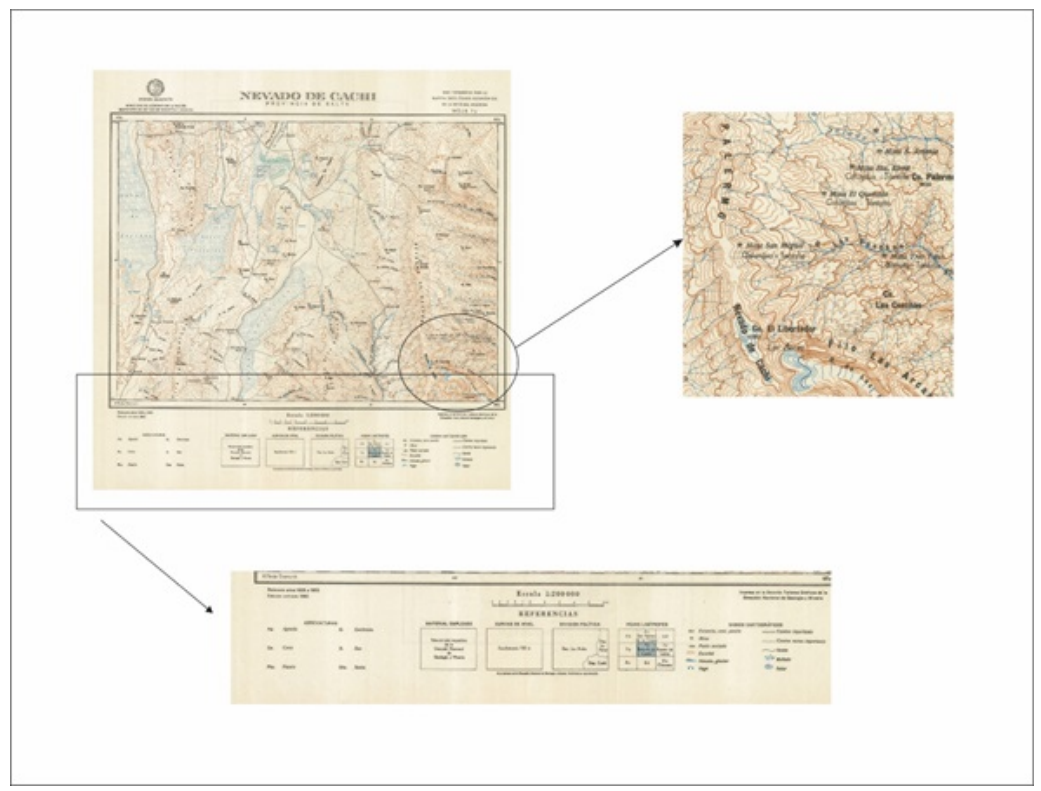

Fuente: Esquema elaboración propia con datos del SEGEMAR.

De manera tal que la centralización de la topografía en una sola institución no significaba que fuera la única autorizada para relevar el territorio; la centralización de la topografía hasta la década de 1980 significó específicamente la limitación de la toma de decisiones gráficas y técnicas para consolidar y publicar los resultados de los levantamientos, y para visualizar el terreno. Esto llevó a una pérdida de la particularidad 
de cada institución para relevar el terreno, en donde se inscribía la singularidad de la mirada que estaba en función de los objetivos del trabajo. Tal como lo planteó el jefe de la sección de topografía de la DMGeH en la década de 1940:

\begin{abstract}
No olvidar en ningún momento cuál es la finalidad del estudio que está realizando. Existen para los geólogos ciertos detalles que para el topógrafo (...) resultan insignificantes al no estar dentro de la escala que se le encomendó, pero que puede resultar la clave de lo que el geólogo investiga. Ejemplo dentro de un gran valle cubierto de rodados, arbustos etc., aparecen uno o más mogotitos de roca firme (este debe registrarse con un llamado especial, ya que a sabiendas no podrá anotarse en la carta, por escapar a la escala). Este pequeño accidente puede alterar fundamentalmente todo un programa de exploración de aguas subterráneas (Carnacini, 1953, p. 14).
\end{abstract}

Creemos que la centralización que produjo la Ley de la Carta es expresiva de la atenuación de las miradas diversas del territorio, de su circulación pública, y de la pérdida de autonomía institucional en la toma de decisiones técnicas y visuales, que borra tanto la autoría individual como la institucional, en beneficio de una representación "posible" que hace centro en el fortalecimiento de la soberanía y la consolidación de liderazgos técnicos en la administración estatal.

\title{
ConCLusión
}

En la Argentina hubo diferentes intentos institucionales por parte del Estado para centralizar la actividad minera y geológica del país. El primer antecedente puede ubicarse en 1857 con la creación de la Inspección de Minas a cargo de Augusto Bravard. Más tarde otro intento se dio con el nombramiento de Ignacio Richard como inspector de Minas de la República en 1868. Sin embargo, para la centralidad institucional hubo que esperar a 1887 cuando se creó el Departamento de Minas, Geología e Hidrología bajo la jefatura de Hoskold, que en 1898 pasó a ser la División de Minas y Geología. En 1904, tras fusionarse con la Comisión de Estudios de Napas y Yacimientos Carboníferos pasó a ser la Dirección de Minas, Geología e Hidrología, bajo la dirección de Hermitte. En 1911 la Dirección propuso un plan cartográfico de largo aliento, que superaba las posibilidades técnicas y financieras con que la institución contaba. A pesar de eso, el plan GeológicoEconómico de la República Argentina estuvo en marcha desde 1911 hasta la década de 1980, cuando su topografía fue remplazada por la que producía el Instituto Geográfico Militar.

En la década de 1940, tras la sanción de la Ley de la Carta, la visualidad de las hojas topográficas de la DMGeH sufrió cambios significativos que llevaron a la pérdida de la especificación técnica y de dibujo. Dicho de otra manera, las consecuencias de la Ley de la Carta llevaron a la pérdida de las miradas diversas del territorio, a la pérdida de autonomía institucional en la toma de decisiones técnicas y visuales, ya que borró tanto la autoría individual como la institucional, en beneficio de una representación "posible" que hace centro en el fortalecimiento de la soberanía y la consolidación de liderazgos técnicos en la administración estatal.

\section{Agradecimientos}

Queremos agradecer la colaboración de la licenciada Silvia Chávez, responsable de la Unidad de Sensores Remotos y SIG del SEGEMAR.

\section{BibLiografía}

Benedetti, A. y Salizzi, E. (2014). Fronteras en la construcción del territorio argentino. Cuadernos de Geografía: Revista Colombiana de Geografía, 23(2), 121-138. Recuperado de https://revistas.unal.edu.co/index.php/rcg/article/v iew/38366/46122 
Camacho, H. (2002). Antecedentes históricos de la formación de los primeros geólogos argentinos. Serie Técnica y Didáctica 2: 1-8. Buenos Aires: Fundación de Historia Natural Félix de Azara.

Camacho, H. 2008. La contribución de la Dirección General de Minas, Geología e Hidrología de la Nación a la formación de la primera generación de geólogos argentinos, y la actuación del Ing. Enrique M. Hermitte. En F.G. Aceñolaza (Ed.), Serie Correlación Geológica: Vol. 24. Los geólogos y la geología en la Historia Argentina (pp. 103-108). Buenos Aires: Instituto Superior de Correlación Geológica (INSUGEO).

Castro, H. (2004). Las "ventajas naturales" del noroeste: Relatos de viaje y construcción de la naturaleza en la Argentina de entre siglos (Tesis de Maestría), Facultad de Filosofía y Letras - UBA, Buenos Aires, Argentina. Recuperada de http://repositorio.filo.uba.ar/handle/filodigital/1815

Crone, G. R. (2000). Historia de los mapas. España: FCE.

Favelukes, G. (2011). Miradas atentas, dibujos precisos, territorios esquivos. Actas de Las I Jornadas de Visualidad y Espacio: Imágenes y Narrativas, Argentina. Paraná: UADER.

García, S. (2016). “Hermitte Enrique Martín”. En I. Pogdorny (Dir.), Diccionario Histórico de las Ciencias de la Tierra en Argentina (pp. 207-209). Rosario: Prohistoria.

Lois, C. (2004). La invención de la tradición cartográfica. Litorales. Teoría, método y técnica en geografía y otras ciencias sociales, 4. Recuperado de http://www.litorales.filo.uba.ar

Mazzitelli Mastricchio, M. (2007). "La Carta de la República”: antecedentes, plan y desarrollo del proyecto cartográfico del Instituto Geográfico Militar. En Lorenzano (ed.), Historia de la Ciencia Argentina III (pp. 20-27). Buenos Aires: Universidad Nacional de Tres de Febrero.

Mazzitelli Mastricchio, M. (2008). Límite y cartografía en la frontera argentina durante el último tercio del siglo XIX. En H. Mendoza Vargas y C. Lois (Comp.), Historia de la ciencia cartográfica de Iberoamérica (pp. 23-35). México: UNAM.

Mazzitelli Mastricchio, M. (2012). La ciencia y la política: Dos aspectos intrínsecos del saber cartográfico argentino [1912-1941]. Geograficando, 8(8), Recuperado de https://www.geograficando.fahce.unlp.edu.ar/arti

Mazzitelli Mastricchio, M. (2017). Imaginar, medir, representar y reproducir el territorio. Una historia de las prácticas y las políticas cartográficas del Estado argentino 1904-1941. Cuadernos Territorio, 17(18), 161. Recuperada de http://publicaciones.filo.uba.ar/series-monogr\%C3\%Alficas-cuadernos-de-territorio

Mazzitelli Mastricchio, M. y Lois, C. (Octubre, 2004). Pensar y representar el territorio: dispositivos legales que moldearon la representación oficial del territorio del Estado argentino en la primera mitad del siglo XX. Trabajo presentado en el 4to Congreso Virtual de Antropología y Arqueología. NAyA, Buenos Aires. Recuperada de http s://www.equiponaya.com.ar/congreso2004/ponencias/carla_lois.htm

Nadal, F. y Urteaga, L. (1990). Cartografía y Estado. Los mapas topográficos nacionales y la estadística en el siglo XIX. Geocritica, 88(88), (1-63). Recuperado de http://www.ub.edu/geocrit/geo88.htm

Newburgh, F. y Protkin, M. (Comps.) (2004). Intelectuales y expertos. La constitución del conocimiento social en Argentina. Buenos Aires: Paidós.

Page, R., Mendía, J., Mazzitelli Mastricchio, M. y Folguera, A. (2014). Historia e interpretación del relevamiento geológico sistemático de la República Argentina: el programa de la carta geológica-económica a escala 1:200.000. Actas del XIX Congreso de Geología, Argentina. Córdoba: Editorial.

Plotkin, M. y Zimmermann, E. (Comp.) (2012). Los saberes del Estado. Buenos Aires: Edhasa.

Reverberi, O. V. (2004). Organismos Nacionales de Minería, cronología de su organización y evolución. En E. Lavandaio y E. Catalano (Ed.) Historia de la Minería argentina: Vol. I. Buenos Aires: Anales 40, SEGEMAR.

Riccardi, A. (2016). Servicio Geológico Minero Argentino. En I. Pogdorny (Dir.) Diccionario Histórico de las Ciencias de la Tierra en Argentina, (pp. 349-351). Rosario: Prohistoria.

Rieznik, M. y Lois, C. (2010). 'En el sendero glorioso de la ciencia universal'. La carte internationale du monde 1:1.000.000, la carte du ciel y la práctica de representación del territorio argentino, 1890-1920”. Llull: Revista de la Sociedad Española de Historia de las Ciencias y de las Técnica, 34(73), 121-160. 
SEGEMAR (2004). 100 años al servicio del desarrollo nacional. 1904-200. Buenos Aires: Ministerio de Planificación Federal, Inversiones Públicas y Servicios.

\section{FUENTES}

Carnacini, O. (1953). Consejos para jóvenes topógrafos. Buenos Aires: Dirección Nacional de Minas, Geología e Hidrología.

Dirección Nacional de Minas, Geología e Hidrología (1912-1944), Memoria (Vol. 1). Buenos Aires: Ministerio de Agricultura.

Decreto $N^{o} 4176$ (1885), Registro oficial de la República Argentina. Comprende documentos de 1810-1873. Tomo IV, Buenos Aires: Publicación Oficial

Decreto No 5071 (1885), Registro oficial de la República Argentina. Comprende documentos de 1810-1873. Tomo IV, Buenos Aires: Publicación Oficial

Decreto $N^{\circ} 7204$ (1885), Registro oficial de la República Argentina. Comprende documentos de 1810-1873. Tomo IV, Buenos Aires: Publicación Oficial

Hermitte, E. (1914), Introducción, en Memoria (Vol. 1). Buenos Aires: Ministerio de Agricultura

IGM. (1979). 100 años en el quehacer cartográfico del país (1879-1979). Buenos Aires: IGM.

IGM. (1912-1951). Anuario del Instituto Geográfico Militar de la República Argentina (Vol. 1). Buenos Aires: IGM.

Rickard I. (1869). Informe sobre los Distritos Minerales. Minas y establecimientos de la República Argentina 1868-1869. Buenos Aires: Ministerio del Interior.

Argentina. Ministerio de Hacienda, Registro Oficial de la República Argentina (1852 - 1890) (2020). Recuperado de http://cdi.mecon.gob.ar/greenstone/cgi-bin/library.cgi?e=d-01000-00---off-0registr1--00-1----0-10-0---0--0direct-10---4------0-0l--11-es-50---20-about---00-3-1-00-0--4--0--0-0-11-10-0utfZz-8-00\&a=p\&p=about

\section{Notas}

1 Durante el período de la Confederación Argentina, el territorio confederado no se limitaba solo a su capital, la ciudad de Paraná, sino que se extendía a toda la provincia entrerriana.

2 El proyecto quedó a cargo de don Sebastián Friaca y se proponía establecer la delimitación entre la propiedad privada de la iglesia, los privados y los terrenos públicos, al mismo tiempo se levantaría el perfil de todas las calles de la capital con el objetivo de nivelar y realizar el empedrado y los desagües. Los planos serían hechos a escala 1:500 y se le entregaría a la iglesia para que conociera el límite de sus propiedades. La importancia técnica radicaba en trazar una "meridiana en el punto que le señale el Gobierno, a fin de que sirva de norma a los trabajos futuros de agrimensura” (decreto 5071, 1860). Un año después del cierre de la Inspección General de Minas se creó el Departamento Topográfico de Entre Ríos, que fue la institución encargada de realizar el levantamiento catastral de la provincia. Para una historia del Departamento Topográfico véase Mazzitelli Mastricchio, 2017.

3 Por ejemplo, en San Luis debía ir a las Carolinas; en Mendoza las minas de Uspallata y Paramillo; en San Juan, la minas de Tontal, Castaño Huachi y la Huerta; en la provincia de la Rioja, la mina de Famatina; en Catamarca debía pasar por Capillitas; también debía pasar por Córdoba.

4 Para la misma época existían otros trabajos de geólogos contratados por el Estado, como los que realizó el alemán Brackebush. Este intelectual llegó a la Argentina en 1875, como consecuencia de la ley aprobada por el ejecutivo en 1869 que autorizó la contratación de expertos para que se dedicaran a la enseñanza en las universidades y colegios recientemente nacionalizados. Sin embargo, creemos que el trabajo de Richard es un indicio y un antecedente de la Dirección de Minas Geología por el tipo de funciones que se le otorgan, es decir, que Richard no enseña geología o mineralogía, este Inspector releva el estado de la minería en tanto recurso económico para el Estado nacional. Brackebuch tuvo gran importancia para la disciplina Geología y el relevamiento geológico, sin embargo, coincidimos con Castro (2002) que estos intelectuales eran viajeros del Estado, ya que eran contratados por este, pero distaban mucho de ser los expertos del Estado o técnicos que empezaban a conformar la planta estatal (Plotkin, y Zimmermann, 2012). Sobre el trabajo de Brackebush véase Mazzitelli Mastricchio y Folguera, 2019.

5 En 1870, por ejemplo, se nombró a Raimundo Lima para el colegio Nacional de Catamarca 
6 Hoskold fue miembro de diversas academias científicas, entre ellas el Instituto de Ingenieros Mineros, Civiles y Mecánicos del norte de Inglaterra; socio de la Sociedad Real de Geografía y de la Sociedad de Geología. Fue miembro de la Sociedad de Ciencias, Artes y Manufactura de Londres y miembro del Instituto de Ingenieros Militares de Norteamérica, entre otras (SEGEMAR, 2004).

7 Hermitte nació en Buenos Aires, pero obtuvo su título de ingeniero civil en Minas en la Escuela Superior de Minas de París, que luego, en 1901, revalidó en la Universidad de Buenos Aires. Antes de estar a cargo de la Comisión se desempeñó como funcionario del Estado en diferentes campos: entre 1897-1898 fue el ingeniero de la Comisión de Límites con Chile y participó de la Dirección General de Vías de Comunicación (García, 2016).

8 Entre 1909 y 1913 se contrataron seis geólogos alemanes: Anselmo Windhausen (1909); Heinrich Gerth (1910), Pablo Groeber (1911), Richard Wichmann (1912), Juan Rassmuss y Walther Penk. Otros profesionales extranjeros contratados fueron el suizo Roberto Beder, el sueco Helge Backlund y el italiano Guido Bonarlli, contratado en 1907 para ocuparse de la explotación petrolera (Riccardi, 2016).

9 Por ejemplo, Hermitte fue uno de los integrantes de Comisión de la Carta que se organizaba en el Instituto Geográfico Militar en 1913 junto a otros científicos que también ocupaban cargos institucionales. Algunos de ellos fueron el secretario jefe de la sección de Geodesia del IGM, doctor en Ciencias Guillermo Schulz, el capitán de navío D. Luis Maurette, jefe de la División de Hidrografía (Ministerio de Marina), el ingeniero Zacarías Sánchez, jefe de la División de Límites Internacionales (Ministerio de Relaciones Exteriores), ingeniero D. Carlos de Chapearouge, jefe de la División de Cartografía de la Dirección General de Ferrocarriles (Ministerio de Obras Públicas), el doctor William Joseph Huissey, director del Observatorio Astronómico de la Plata (Ministerio de Instrucción Pública), el doctor Isidro Ruiz Moreno, director de Territorios Nacionales, D. Juan N. Huber, jefe de la Sección Técnica de la Dirección de Telégrafos (Ministerio del Interior) y el Ingeniero D. Federico Bazzano por el Ministerio de Hacienda (IGM, 1913, p. 69).

10 En este trabajo solo analizamos las hojas topográficas que han sido publicadas. No obstante, es importante destacar que existe una gran cantidad de originales de campo a escala 1:100.000 que nunca fueron publicados por la institución y que pueden ser consultados en el Servicio Geológico Minera Argentino.

11 Debido a que en cartografía las hojas nuevas suelen ser consideradas mejores, y por lo tanto más precisas, las anteriores son descartadas. Esto dificulta el hallazgo de hojas del mismo lugar realizadas en dos momentos históricos diferentes.

12 Es importante destacar que los originales de campo a escala 1:100:000 que se encuentran en la SEGEMAR todos tienen la firma de los topógrafos que realizaron el levantamiento. 